volunteers, especially those who gave blood specimens, without whom the investigation would not have been possible.

\section{REFERENCES}

Davenport, F. M., Hennessy, A. V., Houser, H. B., and Cryns, W. F. (1956). Amer. f. Hyg., 64, 304.

Himmelweit, F. (1960). Brit. med. F., 2, 1690.
Hobson, D., Lane, C. A., Beare, A. S., and Chivers, C. P. (1964). Brit. med. $\ddot{\text {. }}, 2,271$.

McDonald, J. C. (1958). Proc. roy. Soc. Med., 51, 1016

Medical Research Council Committee on Clinical Trials of Influenza Vaccine (1955). Brit. med. F., 2, 1229.

(1957). Ibid., 2, 1.

Meiklejohn, G. (1962). f. Amer. med. Ass., 179, 594.

Philip, R. N., Bell, J. A., Davis, D. J., Beam, M. O., and Beigelman, P. M. (1954). Amer. f. publ. Hlth, 44, 34.

\title{
Serological Studies on Adult Volunteers Inoculated with Oil-adjuvant Asian Influenza Vaccine
}

\author{
Report to the M.R.C. Committee on Influenza and Other Respiratory Virus Vaccines
}

\author{
D. HOBSON,*† M.D. ; CHRISTINE A. LANE,* B.SC. ; A. S. BEARE, $\neq$ M.B., B.CH., D.T.M.\&H. \\ C. P. CHIVERS,§ M.B., CH.B., D.I.H.
}

Brit. med.7., 1964, 2, 271-274

In the autumn of 1960 a large-scale field trial into the efficiency of oil-adjuvant influenza vaccines was initiated by the Medical Research Council (1964). Although the main purpose was to evaluate the protective effect of this new form of vaccine against clinical influenza, it was felt that long-term serological studies were an integral part of the assessment. Accordingly the present investigation was undertaken at the request of the M.R.C. Committee in a group of industrial workers in the Alkali Division of Imperial Chemical Industries Ltd., at Northwich, Cheshire, who were vaccinated in the course of the main trial.

It seemed of particular interest to determine whether the serological response to Asian virus vaccine could be augmented by oil adjuvant, since earlier vaccine trials with these new strains-for example, Clarke et al. (1958), Himmelweit (1960), and Hobson and Pearson (1961)-gave variable results both with saline suspensions of inactivated virus and with virus adsorbed to aluminium phosphate. Antibody induction appeared to be slight, with considerable variation from person to person, and antibody production was not of long duration.

In the present survey serum samples were taken before and at various intervals after inoculation of a single intramuscular injection of oil-adjuvant vaccine. The particular points of study were (a) the duration and degree of serological response in the group as a whole in terms of haemagglutinationinhibiting (H.I.) antibody ; (b) the effect on individual responses of various factors such as age and prevaccination immune status, and $(c)$ the effect of a second dose of vaccine in approximately half the group one year after the first injection, as compared with the antibody response obtained in fresh volunteers.

\section{Materials and Methods}

Vaccination Procedures.-The vaccine consisted of formalininactivated $\mathrm{A} /$ Singapore $/ 1 / 57$ virus blended with an equal volume of Drakeol No. $6 \mathrm{R}$ containing $10 \%$ Arlacel $\mathrm{A}$, to give a final concentration of 2,000 haemagglutination units (H.A.U.) per $0.25-\mathrm{ml}$. dose. Details of the vaccine preparation are described by Himmelweit (1960) and M.R.C. (1964). The

\footnotetext{
- University of Sheffield Virus Research Laboratory, Lodge Moor Hospital, Sheffield.

† Present address : Virus Division, Evans Medical Ltd., Speke, Liverpool. ¥ Central Public Health Laboratory, Colindale Avenue, London. I Medical Department, Alkali Division, I.C.I. Ltd., Northwich, Cheshire.
}

vaccine was dispensed into single-dose containers. Sixty-two staff volunteers (with approximately equal numbers of men and women of under 30 or over 40 years of age) were selected for serological study from a clinical trial population of 2,163 industrial workers receiving adjuvant influenza vaccines in December 1960. Clinical evaluation on this group and the larger trial population is described in the main M.R.C. (1964) study. Blood samples were taken one month before, and at 1,3 , and 12 months after vaccination. At this time (December 1961) 25 of the original group received a second inoculation of the original vaccine which had been stored at $4^{\circ} \mathrm{C}$. for one year, and 25 new volunteers not previously vaccinated were similarly inoculated. Further blood samples were taken 4, 11 , and 16 months after the second injection-that is, 16, 23, and 28 months after the original inoculation.

Haemagglutination-inhibition Tests.-All sera were stored at $-20^{\circ}$ C., and so far as possible all samples from the same person were titrated in parallel in the same batch of tests. H.I. tests were performed by the plastic plate method (W.H.O., 1953), using 8 H.A. units of uninactivated virus. In tests with the A2/Pakistan/1/57 strain sera were inactivated at $56^{\circ} \mathrm{C}$. for 30 minutes before testing. In subsequent titrations with an avid strain of A2/Sing/1/57 sera were pretreated with cholera filtrate (Philips-Duphar) prior to heat-inactivation.

Tissue-culture-neutralization Test.-Details of the method are as described by Pereira (1958) and Beare (1962). In the present tests an allantoic fluid pool of an avid strain of A2/Sing/1/57 was used. Infectivity titres were determined on monkey-kidney-tissue cultures, using a haemadsorption technique (Vogel and Shelokov, 1957). A fixed dosage of virus (final 100 haemadsorption doses) was incubated at $37^{\circ} \mathrm{C}$. for one hour with a final $1 / 10$ dilution of heat-inactivated serum, and the serum-virus mixture then inoculated into monkeykidney tubes. After incubation at $37^{\circ} \mathrm{C}$. for two days the tubes were examined for haemadsorption. Only complete inhibition of haemadsorption was accepted as evidence that the serum contained neutralizing antibody.

\section{Degree and Duration of Antibody Response to Vaccination}

The $\mathrm{A} 2 / \mathrm{Pak} / 1 / 57$ strain of virus was selected for the H.I. tests discussed below, because its insensitivity to non-specific inhibitors of haemagglutination allowed the direct titration of 
sera without the necessity for their pretreatment with such agents as cholera filtrate, sodium periodate, or trypsin (Himmelweit, 1960). Thus the risk of inadvertent destruction of lowtitre specific antibody which exists with all methods of inhibitor-removal could be avoided. There is no apparent antigenic difference between $\mathrm{A} 2 / \mathrm{Pak} / 1 / 57$ and the strain $\mathrm{A} 2 / \mathrm{Sing} / 1 / 57$ employed in the vaccine. The overall results of vaccination expressed conventionally by geometric mean titres (G.M.T.) and median titres are shown in Table I. However, the wide scatter in response makes it essential to consider these indices in relation to the frequency distribution of individual antibody titres at various intervals after vaccination (Fig. 1).

TABLE I.-Geometric Mean Titres of H.I. Antibody to A2/Pak/1/57 in Adult Volunteers Given a Single Dose of Oil-adiuvant A2/Sing/1/57 Adult Volunters Given a Single Dose of Oil-adiuvant
Vaccine or Two Doses at an Interval of 12 Months

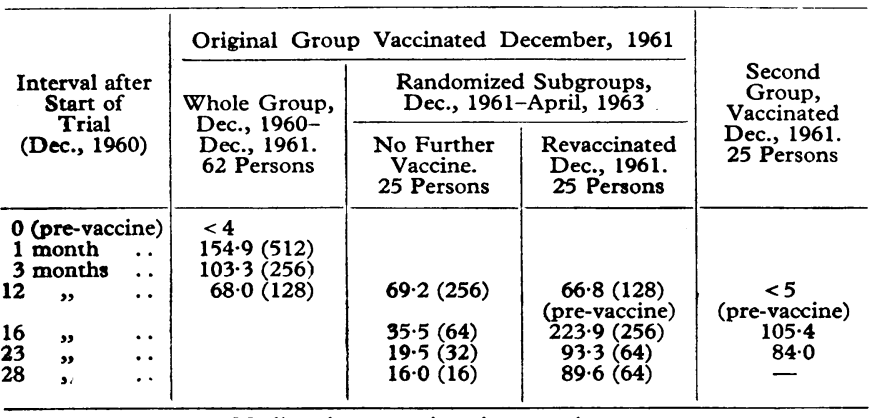

Median titres are given in parentheses.

PRE-VACCINE. 52/54 SERA SHOWED NO ANTIBODY AT I/4

I MONTH POST-VACCINE
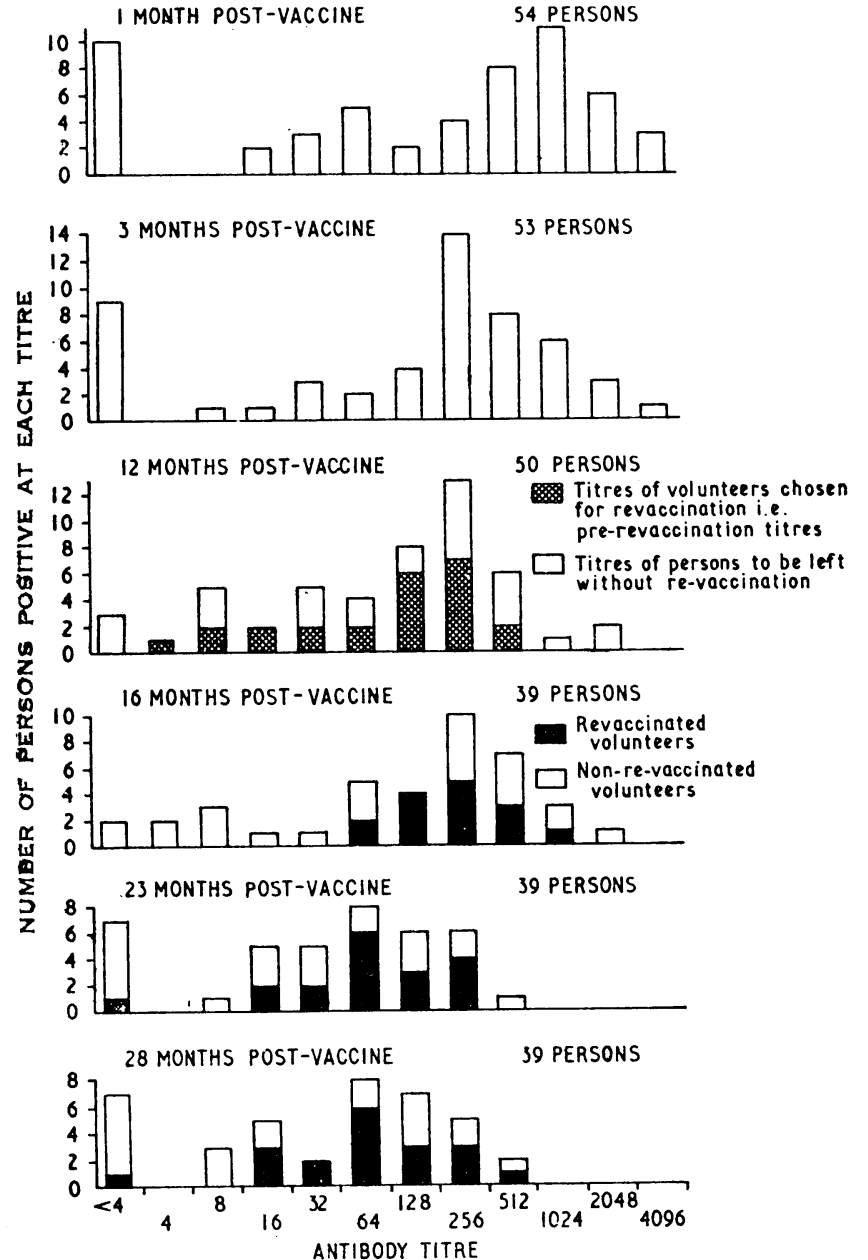

FIG. 1.-Distribution of H.I. antibody titres to $A 2 / \mathrm{Pak} / 1 / 57$ in adult volunteers given an oil-ad uvant vaccine of $\mathrm{A} 2 / \mathrm{Sing} / 1 / 57$ once, or on two occasions at a 12-month interval.
Before vaccination only $2(3.7 \%)$ out of 54 sera contained detectable H.I. antibody, with titres of $1 / 4$ and $1 / 8$.

One month after vaccination the G.M.T. of the group had risen to a peak level of 154.9. However, despite the apparently uniform non-immune pre-vaccine status of the population, postvaccine titres fell into two relatively distinct groups-firstly, a group of 34 persons $(64 \%$ ) with titres of $1 / 128-1 / 2048$, and, secondly, a group of $20(36 \%)$ showing no serological response, or titres of $1 / 64$ or less.

Three months after vaccination the G.M.T. had fallen to 103.3. The bimodal distribution of titres persisted, with 16 of the original 20 individuals still with little or no detectable H.I. antibody. These results suggest that the wide scatter of antibody response could not be attributed to individual variations in the time taken to attain peak titre after vaccination. In fact, no persons showed a significant further rise in antibody between the first and third months, and in several cases a fall had occurred. Further investigation of the poor immunization of certain individuals is considered below.

Twelve months after vaccination $34(68 \%)$ out of 50 persons examined retained antibody levels of $1 / 128$ or greater, although the G.M.T. of the group had fallen to 68.0.

At this stage the population was randomly divided; 25 persons (G.M.T. 69.2) continued under observation without further inoculation while the remaining 25 (G.M.T. 66.8) received a second dose of the adjuvant vaccine. A new group of 25 volunteers not previously immunized (G.M.T. <5) were vaccinated at the same time with the same material.

Four months later (16 months after the original inoculation) the original population available for further tests had fallen from 50 to 40 persons, of whom 18 had been revaccinated, thus exact comparison with earlier results could not be made. However, $10(45.5 \%)$ out of 22 of those not revaccinated continued to show antibody levels of $1 / 128$ or greater, although the G.M.T. of this subgroup had fallen to 35.5. In contrast, $16(89 \%)$ out of 18 of the revaccinated subgroup now had antibody titres of $1 / 128$ or greater and the G.M.T. had risen to 223.9. In the new group of volunteers at this time, four months after vaccination, the G.M.T. was 105.4 , a value closely similar to that found at a comparable interval after vaccination of the original group with the same material one year earlier.

Twenty-eight months after the initial vaccination antibody levels of $1 / 128$ or above still persisted in $9(45 \%)$ out of 20 of the non-revaccinated group, though the overall scatter of titres towards lower levels had increased, and the G.M.T. had fallen to 16.0. In the revaccinated group, antibody levels had declined somewhat from the peak levels induced by the second dose, with only $7(39 \%)$ out of 18 still showing antibody levels of $1 / 128$ or above. However, the scatter of antibody titres was less than in the single-dose group, and this is reflected by the G.M.T. value of 99.6 .

\section{Bimodal Distribution of Antibody Titres after Vaccination}

As described above, $10(18 \%)$ out of 54 persons failed to develop H.I. antibody detectable by $\mathrm{A} 2 / \mathrm{Pak} / 1 / 57$ and in a further 10 titres were $1 / 64$ or less, one month after vaccination, in distinction to the majority of the group with a peak frequency of 512-1024. Since further examination showed that these individuals were not slow reactors with a later-thannormal rise to peak titres, other possibilities were considered.

It seemed possible that, despite the apparent absence of H.I. antibody in prevaccination sera, individuals did, in fact, vary in their previous experience of Asian virus. It seemed likely that persons with a poor response to vaccine were undergoing a primary antigenic stimulus, whereas those with high-titre responses were giving a secondary immune response because of previous exposure to Asian virus antigens. Further investigations of pre-vaccine sera were made in an attempt to 
demonstrate residual immunity from past exposure. Since $\mathrm{A} 2 / \mathrm{Pak} / 1 / 57$ is highly insensitive to non-specific inhibitorssuch as the factor in normal horse serum described by Cohen and Belyavin (1959)-it seemed likely that the strain was also non-avid, and incapable of detecting low titres of resting antibody. Hence selected sera were retested for H.I. antibody against an avid mouse-adapted strain of $\mathrm{A} 2 / \mathrm{Sing} / 1 / 57$. Since this strain was highly sensitive to non-specific inhibitors, all sera were treated with cholera filtrate before titration.

The titres of post-vaccine antibody were fourfold to sixfold higher than those observed with $\mathrm{A} 2 / \mathrm{Pak} / 1 / 57$, and almost half of the pre-vaccine sera, negative when tested with the latter virus, were capable of some H.I. with $A 2 /$ Sing/1/57. Titres, however, were low $(1 / 4-1 / 16)$, and it could not easily be determined whether the effect was in fact due to specific antibody and not to traces of non-specific inhibitor which had escaped the action of cholera filtrate. For this reason, all prevaccine sera were re-examined for specific neutralizing antibody to $A 2 / \operatorname{Sing} / 1 / 57$ in monkey-kidney-tissue culture (Pereira, 1958). The same allantoic fluid pool of virus was used as in the H.I. tests described above.

The results (Fig. 2 and Table II) showed that the prevaccination status of the volunteers in the terms of neutralizing antibody was closely correlated with the degree of H.I. antibody response to vaccine. Only $4(20 \%)$ out of 20 persons without initial neutralizing antibody developed H.I. titres of $1 / 128$ or greater after vaccination, as compared with $30 / 34(88.2 \%)$ out of 34 subjects with revaccination neutralizing antibody $\left(x^{2}=22\right.$, significant at $0.1 \%$ level).

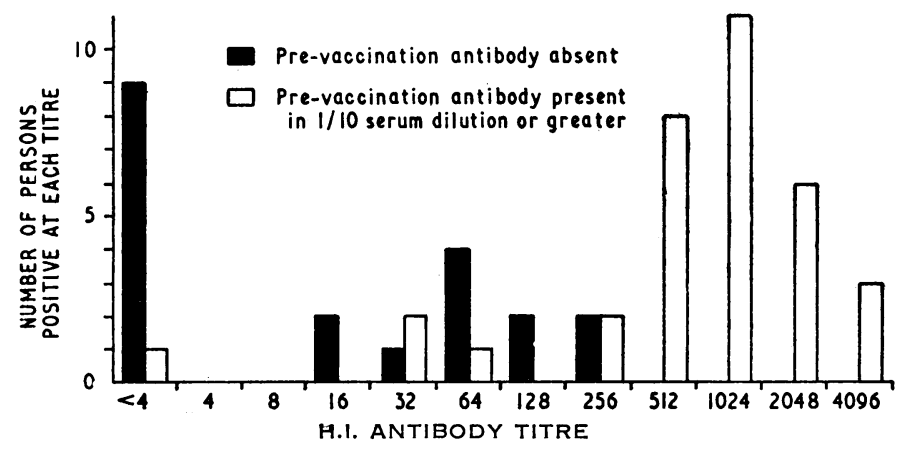

FIG. 2.-Relation between pre-vaccination neutralizing antibody to A2/ Sing / 1/57 virus and the $\mathrm{H}$.I. antibody response to $\mathrm{A} 2 / \mathrm{Pak} / 1 / 57$ after vaccination with oil-ad;uvant A2/Sing/1/57 vaccine. (Pre-vaccine H.I. titre $<4$ in 52 out of 54 subjects.)

TABLE II.-Relation Between Response to Asian Influenza Vaccine and Presence of Pre-vaccination Neutralizing Antibody (Figures Represent Number of Persons)

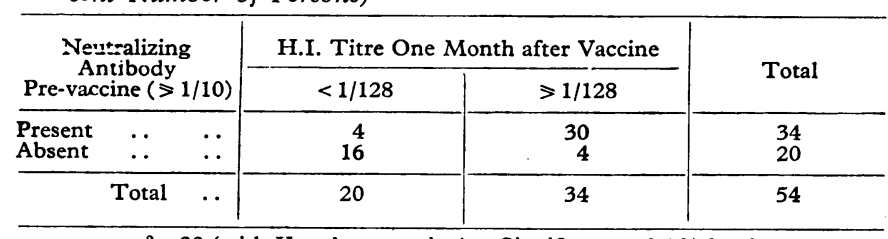

$\chi^{2}=22$ (with Yates's correction). Significant at $0 \cdot 1 \%$ level.

It seemed possible that the age of the individual might have been a determining factor in the degree of response to vaccine, since a higher proportion of young than of older persons were known to have had clinical influenza during the first epidemic waves of Asian virus infection ( $\mathrm{McD}$ onald, personal communication). In fact, neutralizing antibody to A2/Sing/ $1 / 57$ virus was found in the pre-vaccine serum sample of 24 $(80 \%)$ out of 30 adults less than 30 years of age, as compared with $12(50 \%)$ out of 24 in the older age-group. This difference is not highly significant in itself $\left(x^{2}=4.25\right.$, significant at $5 \%$ level), but it is interesting that high and low post-vaccine antibody titres were similarly distributed by age. Thus 25 $(83 \%)$ out of 30 adults under 30 years of age had titres of $1 / 128$ or greater, compared with only $11(46 \%)$ out of 24 of the older age-group $\left(\chi^{2}=6.2\right.$, significant at $1 \%$ level $)$. These findings are summarized in Table III ; it would appear that the degree of antibody response was not directly correlated with the age of the individual, except in so far as the younger group was the more likely to have pre-vaccination immunity and thus to have shown a booster response to vaccine.

TABle III.-Relation Between Age, Pre-vaccination Neutralizing Antbody, and H.I. Antibody Response to Asian Influenza Vaccin (Figures Represent Number of Persons. Total in Group=54)

\begin{tabular}{|c|c|c|c|c|}
\hline \multirow{4}{*}{$\begin{array}{l}\text { Age Group } \\
\text { (Years) }\end{array}$} & \multicolumn{4}{|c|}{ H.I. Titre One Month After Vaccine } \\
\hline & \multicolumn{2}{|c|}{$<1 / 128$} & \multicolumn{2}{|c|}{$>1 / 128$} \\
\hline & \multicolumn{2}{|c|}{$\begin{array}{l}\text { Pre-vaccine Neutralizing } \\
\text { Antibody }\end{array}$} & \multicolumn{2}{|c|}{$\begin{array}{l}\text { Pre-vaccine Neutralizing } \\
\text { Antibody }\end{array}$} \\
\hline & Absent & Present & Absent & Present \\
\hline $\begin{array}{l}>40 \\
<30\end{array}$ & $\begin{array}{r}10 \\
4\end{array}$ & $\begin{array}{l}3 \\
1\end{array}$ & $\begin{array}{l}2 \\
2\end{array}$ & 23 \\
\hline
\end{tabular}

\section{Discussion}

Although the present trial did not involve a direct comparison of influenza vaccine in adjuvant form with conventional saline vaccine, the overall results indicate that the adjuvant preparation is capable of inducing higher peak antibody titres in a higher proportion of subjects than would be expected for saline vaccine, and that the persistence of circulating H.I. antibody is considerably prolonged. In fact, $46(85 \%)$ out of 55 persons showed a significant rise of antibody after a single dose of vaccine, and in no case had antibody declined to prevaccine level within two years after inoculation. It should be stressed that this satisfactory serological picture was obtained following a dosage of virus antigen only one-tenth that customarily used in the form of saline vaccine (Himmelweit, 1960). It was of interest that the titres one month after vaccination were as high or higher than those after three months. This suggests that the combination of vaccine with oil has not impeded the rate of antigen release to an extent which would adversely affect early immunization. Similarly, Salk and Laurent (1952) and Davenport et al. (1956) have shown that the rate of antibody augmentation over the first few weeks after immunization is similar for adjuvant and saline preparations. In these earlier reports, however, antibody titres following adjuvant vaccine continued to rise for several months.

The bimodal distribution of H.I. antibody titres after vaccination suggests that the overall immunizing effect was conditioned to some extent by the previous immune status of the individual. Tissue-culture-neutralization tests and H.I. tests with an avid virus strain indicated that those with previous experience of Asian antigen gave the better serological response to vaccine. Davenport and Hennessy (1956) have shown that influenza vaccines readily produce immunological recall at considerable intervals after the primary antigenic stimulus.

After one year's storage at $4^{\circ} \mathrm{C}$. the original vaccine, given to a fresh group of volunteers, resulted in a pattern of antibody response closely similar to that seen in the original group 12 months earlier. Thus there seems little doubt that the potency of the virus antigens had not deteriorated significantly in the oily adjuvant vehicle on prolonged storage. It was of interest, therefore, that the same vaccine, given to half the original group as a "booster" dose one year after their primary stimulus, produced only a relatively modest, though definite, increase in antibody levels. In fact, the mean rise in titre was less than fourfold, as compared with more than tenfold in the new, previously unimmunized volunteers, and inspection of individual titres showed that no revaccinated subject exceeded the peak antibody level he had attained after the first injection. This may suggest that there is a "ceiling" antibody titre 
characteristic of each individual, and that this maximum immune response was attained after the first dose. Alternatively, it may be speculated that the immunizing effect of a given dosage of influenza virus antigens is relatively suppressed by the presence of circulating antibody, since the lowest percentage rise in antibody titre was obtained in those with the most pre-vaccine antibody.

The somewhat better response of young than of older adults to vaccination would seem to be due to a greater frequency of pre-vaccine experience of Asian antigen in the former agegroup rather than to any inherent difference in responsiveness. In fact, the degree of antibody rise in older adults who did show evidence of pre-vaccine immunity was as great as in those young persons in whom the vaccine was similarly acting as a secondary stimulus. The post-vaccination H.I. antibody titres found in the present group of volunteers appear to be somewhat lower than those found in a small sample drawn from other groups participating in the main trial (M.R.C., 1964), although the same test strain of virus was used in each case. These differences may to some extent be due to differences in sensitivity between the W.H.O. test with fowl red cells used in the present survey and that with human red cells in lithium chloride buffer (Himmelweit, 1960) used in the main trial. However, it may be noted that the higher postvaccine titres found in the main report were largely from individuals with higher pre-vaccine antibody levels than those found in Northwich.

Although H.I. tests with inhibitor-resistant strains such as A2/ Pak/1/57 have the advantage of simplicity, the associated lack of antibody-avidity of such strains may underestimate the serological response to vaccine, and fail to detect pre-vaccine antibody in low titre. Thus persons with previous immune sensitization to Asian antigen in whom the vaccine is not acting as a primary immune stimulus cannot be distinguished. The advantage of the tissue-culture-neutralization test for detecting influenza antibodies has been discussed by Beare (1962), and appears to be equally relevant to this present problem.

\section{Summary}

Adult volunteers given a single intramuscular injection of oil-adjuvant Asian influenza vaccine containing approximately $1 / 10$ the usual antigen content of saline vaccine were selected for long-term serological investigation as part of a large-scale clinical trial by the Medical Research Council.

Peak titres of haemagglutination-inhibiting antibody occurred one month after vaccination ; $44(81.5 \%)$ out of 54 showed a significant rise in antibody, with titres of $1 / 128$ or greater in $34(64 \%)$ subjects. The immune response was greater in persons under 30 than in those over 40.

A small proportion of volunteers had a poor antibody response; these were found to consist of subjects with no evidence of previous experience of Asian virus antigens.

One year after vaccine $34(68 \%)$ out of 50 people continued to show antibody titres of $1 / 128$ or above, and after a further 16 months $9(45 \%)$ out of 20 still had titres of this order.

Revaccination of part of the group 12 months after the initial dose gave an approximately fourfold increase in mean titre. After four months the antibody levels began to decline at almost the same rate as in non-revaccinated subjects.

The immunizing potency of oil-adjuvant vaccine was shown to be substantially unchanged after 12 months' storage at $4^{\circ} \mathrm{C}$.

REFERENCES

Beare, A. S. (1962). Mth. Bull. Minist. Hlth Lab. Serv., 21, 167.

Cohen, A., and Belvavin, G. (1959). Virology, 7, 59.

Clarke, S. K. R., Heath, R. B., Sutton, R. N. P., and Stuart-Harris, C. H. (1958). Lancet, 1, 814.

Davenport, F. M., and Hennessy, A. V. (1956). 7. exp. Med., 104, 85. Houser, H. B., and Cryns, W. F. (1956). Amer. F. Hyg., 64,

Himmelweit, F. (1960). Brit. med. f., 2, 1690.

Hobson, D., and Pearson, E. (1961). Brit. f. exp. Path., 42, 53.

Medical Research Council (1964). Brit. med. F., 2, 267.

Pereira, M. S. (1958). Lancet, 2, 668.

Salk, J. E., and Laurent, A. M. (1952). 7. exp. Med., 95, 429.

Vogel, J., and Shelokov, A. (1957). Science, 126, 358.

World Health Organization Expert Committee on Influenza (1953). Wld Hlth Org. techn. Rep. Serv., No. 64.

\title{
Effects of Bereavement on Physical and Mental Health-a Study of the Medical Records of Widows
}

\author{
C. MURRAY PARKES,* M.D., D.P.M.
}

Brit. med. F., 1964, 2, 274-279

Despite the large amount of research into the pathogenic effects of stress on human beings and animals, little notice has been taken of one of the commoner major psychological stresses, the death of a loved person. This omission is the more remarkable because grief, the psychological reaction to loss of a loved object, has for many years occupied a central place in the psychoanalytic theory of mental illness.

It is now well established that the mortality rate for many causes of death is much higher among widows and widowers than among married persons of the same age. In a careful analysis of the statistical evidence Kraus and Lilienfeld (1959) show that the "effects of widowhood" (grief and the environmental changes which attend it) are the most likely causes of this increased mortality. More recently Young, Benjamin, and Wallis (1963) have shown that a sharp rise in mortality rate takes place during the first six months of widowerhood, and

* From the Tavistock Institute of Human Relations, London W.1. that this is followed by a gradual return to a rate near that of married men of the same age. This initial rise after bereavement does not account for the whole of the increased mortality, however, and these workers conclude that a further rise in mortality must take place after the lapse of a few years.

In view of this increased mortality it is to be expected that major bereavements will also be followed by an increased morbidity. Marris (1958), in his study of 72 young widows located at random through the death registration of their husbands, claims that at the time of interview, one to three years after their bereavement, $43 \%$ thought that their health was worse than it had been before the loss. In the absence of controls, however, it is not possible to say for sure whether the symptoms of which these widows complained might not have been found with equal frequency in a non-bereaved population. 